\title{
Clinical utility of esomeprazole for treatment of gastroesophageal reflux disease in pediatric and adolescent patients
}

This article was published in the following Dove Press journal:

Adolescent Health, Medicine and Therapeutics

25 February 2012

Number of times this article has been viewed

\author{
Sabrina Cardile \\ Claudio Romano \\ Department of Pediatrics, University \\ of Messina, Italy
}

\begin{abstract}
Gastroesophageal reflux is a common condition in the pediatric population, with an increasing incidence in the last few years. It can be defined as an effortless retrograde movement of gastric contents into the esophagus related to complex multifactorial pathogenesis, involving anatomical, hormonal, environmental, and genetic factors. In some cases, it may be associated with esophageal or extraesophageal symptoms (heartburn and regurgitation), and is defined as gastroesophageal reflux disease (GERD). The therapeutic approach to gastroesophageal reflux in infants and children is often conservative, including changes in lifestyle (eg, posture and thickening of meals). If these children remain symptomatic after lifestyle changes (nutrition, feeding, and positional modification), or present with clinical red flags (poor weight gain, recurrent respiratory symptoms, or hematemesis) and complications of GERD (esophagitis, bleeding, stricture, Barrett's esophagus, or adenocarcinoma) it may be necessary to set up a proper diagnostic protocol. Proton pump inhibitors have been recommended as the most effective acid suppression therapy for adults and pediatric patients. Esomeprazole, the S-isomer of omeprazole, is the only single-isomer proton pump inhibitor available. The paper assesses the safety and tolerability of esomeprazole in pediatric and adolescent patients.
\end{abstract}

Keywords: esomeprazole, gastroesophageal reflux disease, pump proton inhibitors

\section{Introduction}

Gastroesophageal reflux is the most common esophageal disease in the pediatric age group, with an incidence of around $15 \%-20 \%$ in the first year of life. Gastroesophageal reflux is an effortless retrograde movement of gastric contents into the esophagus. Gastroesophageal reflux disease (GERD) in pediatric patients is present when reflux of gastric contents is the cause of troublesome symptoms and/or complications. In adults, the approach adopted in the Montreal definition of GERD, has been to use a patientcentered, symptom-based definition, which in children can present several caveats. ${ }^{1}$

\section{Clinical symptoms of GERD}

In children, the definition of when symptoms become troublesome is complicated by several factors, especially in infants and children younger than 8 years of age, and symptoms reported by surrogates (parents or caregivers) may decrease the validity of the diagnosis. ${ }^{2}$ Heartburn and regurgitation are typical symptoms of GERD, and the same is true for older children. Otherwise, healthy newborns (aged 1-30 days) and infants (aged $>30$ days to one year) with reflux symptoms (food refusal, crying, regurgitation) that are not troublesome and are without complications should not be diagnosed with GERD. In infants, normal regurgitation and normal crying, or abnormal
Correspondence: Claudio Romano

Department of Pediatrics,

University of Messina,

Via Consolare Valeria,

98125 Messina, Italy

$\mathrm{Tel}+390902212918$

Fax +39090 221 7005

Email romanoc@unime.it 
crying due to causes other than GERD, may be mistaken for GERD. Both the North American Society for Pediatric Gastroenterology, Hepatology, and Nutrition and the European Society of Pediatric Gastroenterology, Hepatology, and Nutrition recommend using clinical symptoms for diagnosing and evaluating treatment of uncomplicated GERD in infants, ${ }^{3,4}$ and have developed and validated an instrument for assessment of GERD-related symptoms in this age group. The Infant Gastroesophageal Reflux Questionnaire (I-GERQ) was designed and validated as an instrument to obtain baseline clinical information and as a diagnostic questionnaire. It was validated for diagnosis of GERD in children aged 1-14 months by using abnormal $\mathrm{pH}$ probe studies and/or abnormal esophageal biopsies as gold standards. The use of a symptom-based questionnaire, ie, I-GERQ-Revised (I-GERQ-R) can be considered a valid method for evaluating the entity of gastroesophageal reflux symptoms in infants. ${ }^{5}$ In pediatric patients, esophageal complications of GERD include reflux esophagitis, hemorrhage, stricture, and Barrett's esophagus. Erosive esophagitis occurs in more than one third of pediatric age patients if GERD-promoting disorders, such as neurological impairment, esophageal atresia, or Down syndrome, are present. 6,7

\section{Proton pump inhibitors in GERD}

Symptoms of gastroesophageal reflux in infants are often related to immaturity and physiologic reflux, which does not need pharmacologic therapy, but improve with time as the infant matures, and with changes in lifestyle (eg, more solid food and postural habits), education, and reassurance for the parents. Available evidence does not support an empiric trial of acid suppression in infants with unexplained crying, irritability, or sleep disturbance,${ }^{8}$ and medical therapy can be confined to altering the viscosity of the feeds with alginate, or altering the motility of the gut with domperidone. Proton pump inhibitors are the mainstays in treating acid-related disease. Since the introduction of omeprazole in 1989 , other proton pump inhibitors have become available, such as lansoprazole in 1995, pantoprazole in 1997, rabeprazole in 1999, and esomeprazole, the S-enantiomer of omeprazole, in 2001.

Proton pump inhibitors selectively and irreversibly inhibit gastric $\mathrm{H}^{+} / \mathrm{K}^{+}$ATPase (the proton pump) that accomplishes the final step in acid secretion. All proton pump inhibitors inhibit both basal and stimulated secretion of gastric acid, independent of the nature of parietal stimulation. ${ }^{9}$ Proton pump inhibitors undergo extensive hepatic metabolism by the cytochrome P450 (CYP) system, and
CYP2C19 polymorphisms have been shown to influence the pharmacokinetics, pharmacodynamics, and clinical outcome of proton pump inhibitors substantially. ${ }^{10}$ In addition, pharmacokinetic and pharmacodynamic differences between proton pump inhibitors are reflected in their influence on both speed and gastric acid suppression, which subsequently may affect clinical efficacy. Although proton pump inhibitors are more efficient than $\mathrm{H} 2$ receptor antagonists, for many years the latter (especially ranitidine) were used in children. ${ }^{11}$ Proton pump inhibitors are drugs of first choice for peptic ulcers and GERD, with an excellent safety profile and nonspecific adverse events. ${ }^{12}$ Proton pump inhibitors are currently on the market in Europe and the US for the adult population, but only omeprazole and esomeprazole have been licensed for use in children (ie, children aged $\geq 2$ years). ${ }^{13}$ Lansoprazole is recommended by the British National Formulary for children only when treatment with the available formulations of omeprazole is unsuitable. ${ }^{14}$ The US Food and Drug Administration has approved esomeprazole magnesium (Figure 1) for short-term and long-term use in children aged 1-11 years with GERD, in two forms, ie, a delayed-release capsule and granular sachets. The dosage schedule is 10 or $20 \mathrm{mg} /$ day for children aged 1-11 years and 20 or $40 \mathrm{mg}$ /day for those aged $12-17$ years. $^{15}$

Esomeprazole, introduced in 2001, is the $S$-isomer of omeprazole and the first such inhibitor to be developed as a single isomer. It has higher metabolic stability, resulting in better and more consistent bioavailability compared with the racemate, omeprazole. ${ }^{10}$ Esomeprazole is metabolized more slowly than omeprazole, resulting in an increase in the area under the plasma concentration-time curve that provides more effective control of gastric acid secretion even after only a single dose. ${ }^{16}$ In adults, some trials have compared esomeprazole $40 \mathrm{mg}$ with omeprazole $20 \mathrm{mg}$ and lansoprazole $30 \mathrm{mg}$, with evidence that esomeprazole is superior for symptom relief and healing in patients with erosive esophagitis. Röhss et $\mathrm{al}^{17}$ reported that esomeprazole $40 \mathrm{mg}$ once daily demonstrated a significantly greater

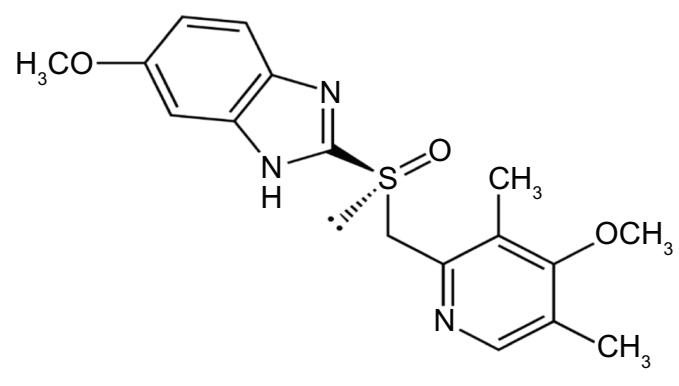

Figure I Structural formula of esomeprazole, S-isomer of omeprazole. 
mean percentage over the 24-hour period with intragastric $\mathrm{pH}>4$ as compared with omeprazole $40 \mathrm{mg}$ once daily. Esomeprazole has been shown to provide better acid control in adults than other proton pump inhibitors, ${ }^{18}$ and is also more effective at healing esophagitis. ${ }^{19}$

As in the adult population, proton pump inhibitors are rapidly absorbed in children following oral administration, with the mean time to maximum plasma concentration varying from $1-3$ hours. ${ }^{20}$ Proton pump inhibitors are more effective than $\mathrm{H} 2$ receptor antagonists for healing and relief of GERD symptoms. Both medications are more effective than placebo. Most children require a daily dose of a proton pump inhibitor to obtain symptomatic relief and heal esophagitis.

\section{Esomeprazole in GERD}

Gunasekaran et $\mathrm{al}^{21}$ evaluated the efficacy of esomeprazole in adolescents with GERD after an 8-week trial in an international randomized study. The burden of illness was measured by a disease-specific health-related quality of life instrument, Quality of Life in Reflux and Dyspepsia questionnaire (QOLRAD, a questionnaire previously validated in adults, which examines emotional distress, sleep disturbance, food/drink problems, vitality, and physical/social functioning). Baseline QOLRAD scores showed significant improvement in health-related quality of life from baseline values after esomeprazole therapy.

A recent international, multicenter, randomized, parallelgroup, double-blind study in children aged 1-11 years with erosive esophagitis confirmed that, after 8 weeks of treatment with esomeprazole once daily $(0.2-1.0 \mathrm{mg} / \mathrm{kg})$, there was significant healing of macroscopic and histological esophagitis $(89 \%$ versus $13 \%$ in placebo group, $P<0.01){ }^{22}$

Zhao et al, ${ }^{23}$ in a randomized, open-label study, assessed the overall exposure, other pharmacokinetic properties, and tolerability of esomeprazole magnesium after repeated oral doses of 5,10 , and $20 \mathrm{mg}$ in pediatric patients who had symptoms of GERD. For this 5-day study, children in the younger age group were randomly assigned to receive one esomeprazole $5 \mathrm{mg}$ or $10 \mathrm{mg}$ capsule, and those in the older age group were randomly assigned to receive one esomeprazole $10 \mathrm{mg}$ or $20 \mathrm{mg}$ capsule. Plasma concentrations of esomeprazole were measured using reverse-phase liquid chromatography and mass spectrometric detection. Tolerability assessments were performed by reviewing the number and severity of adverse events. The results of this small study suggest that, in children aged 1-11 years with GERD, the pharmacokinetic properties of esomeprazole may be both dose-dependent and age-dependent, and that younger children might have more rapid metabolism of esomeprazole per kilogram of body weight compared with older children. Esomeprazole was well tolerated at doses of 5, 10, and $20 \mathrm{mg}$ in the pediatric patients studied.

Gilger et $\mathrm{al}^{24}$ have evaluated the safety, tolerability, and efficacy of symptom improvement using esomeprazole in a multicenter, randomized, uncontrolled, double-blind study in 1-11-year-old children with erosive esophagitis, stratified by weight, who received esomeprazole 5 or $10 \mathrm{mg}$ (children $<20 \mathrm{~kg}$ ), or 10 or $20 \mathrm{mg}$. In total, $9.3 \%$ of patients reported 13 treatment-related adverse events, of which the most common was diarrhea. Parent rating of GERD symptoms of heartburn, acid regurgitation, and epigastric pain showed that $91.4 \%$ had lower scores by the final visit. In conclusion, esomeprazole was well tolerated and safe in this age group, and symptoms from baseline were significantly reduced.

Gold et $\mathrm{al}^{25}$ in a multicenter, randomized, double-blind study assessed the safety of esomeprazole 20 or $40 \mathrm{mg}$ once daily in adolescents with clinically diagnosed GERD, with the secondary aim of assessing changes in GERD symptoms. Twenty-two patients (14.9\%) experienced adverse events that were considered related to treatment; the most common were headache $(8 \%, 12 / 148)$, abdominal pain $(3 \%, 4 / 148)$, nausea $(2 \%, 3 / 148)$, and diarrhea $(2 \%, 3 / 148)$. Symptom scores decreased significantly in both the esomeprazole $20 \mathrm{mg}$ and $40 \mathrm{mg}$ groups by the final study week $(P<0.0001)$. This study has confirmed the significant efficacy and good tolerance of esomeprazole in a pediatric population. Because of the relative paucity of clinical trial data for the pediatric population, it is possible to underline (Table 1) that:

- esomeprazole, the $S$-isomer of omeprazole, has been evaluated in the management of GERD in children aged 1-11 years and adolescents aged 12-17 years

- in an 8-week, randomized, double-blind, multicenter trial, a significant improvement from baseline in parentrated GERD symptom scores was seen in children aged 1-11 years with endoscopically proven GERD, stratified to receive oral esomeprazole 5 or $10 \mathrm{mg}$ (in those weighing $<20 \mathrm{~kg}$ ), or 10 or $20 \mathrm{mg}$ (in those weighing $\geq 20 \mathrm{~kg}$ ) once daily; a substudy demonstrated improved or healed

Table I Efficacy of esomeprazole in pediatric GERD

It has been evaluated in the management of GERD in children It improved or healed erosive esophagitis in the majority of children $40 \mathrm{mg}$ once daily is more efficacious than $20 \mathrm{mg}$ It is a safe therapy in the short to medium term (4-8 weeks)

Abbreviation: GERD, gastroesophageal reflux disease. 
erosive esophagitis in the majority of children following esomeprazole therapy

- children treated with $40 \mathrm{mg}$ once daily had lower symptom scores and a numerically shorter median time to sustained symptom resolution than those in the $20 \mathrm{mg}$ group

- esomeprazole was generally well tolerated in children with GERD aged 1-11 years and adolescents aged 12-17 years, according to the results of well designed, short-term trials.

More studies are needed to determine better the effective duration of therapy, and according to which criteria proton pump inhibitors should be discontinued. Moreover, it is important that further research be undertaken to characterize what can be considered the natural history of GERD and factors correlated with the risk of complications. Hassall et al in a retrospective cohort study investigated children who had received proton pump inhibitor therapy continuously for more than 9 months, concluding that proton pump inhibitors are efficacious and safe in the long term, with significant symptomatic improvement, noting a very low incidence of adverse reactions. ${ }^{26}$

The long-term use of proton pump inhibitors may be safe in pediatric patients, ${ }^{27}$ even if some adverse events have been reported, such as diarrhea, drowsiness, ${ }^{25}$ an increased incidence of Clostridium difficile infection, ${ }^{28}$ an increased risk of acute gastroenteritis and community-acquired pneumonia, ${ }^{29}$ effects on vitamin B12 and vitamin C, altered absorption of non-heme iron, ${ }^{30}$ risk of hip fracture, ${ }^{31}$ increased serum levels of gastrin and enterochromaffin-like cells, and atrophic gastritis. Some studies have demonstrated minor degrees of enterochromaffin-like hyperplasia, without a risk of developing atrophic gastritis or carcinoid tumors, in a high percentage of children $(61 \%)$ receiving a long-term proton pump inhibitor continuously for up to 10.8 (median 2.84) years. ${ }^{32,33}$ Significantly higher urinary N-nitrosamine excretion has been demonstrated in the adult population, indicating a risk of increased endogenous N-nitrosamine formation during long-term omeprazole treatment. ${ }^{34}$

The safety and tolerability of acid-suppressive agents in pediatric patients is an important concern for physicians and parents alike. The major indications for use of proton

Table 2 Indications for proton pump inhibitors in infants and children

Healing of acute erosive esophagitis

Maintaining remission in patients with erosive esophagitis

Symptomatic relief of nonerosive reflux disease

Nocturnal acid secretion and relevant reflux

Supraesophageal symptoms of GERD

Abbreviation: GERD, gastroesophageal reflux disease. pump inhibitors can be considered to be healing of acute erosive esophagitis, maintaining remission in patients with erosive esophagitis, symptomatic relief of nonerosive reflux disease, nocturnal acid secretion and relevant reflux, and supraesophageal symptoms of GERD. ${ }^{35}$ In pediatric populations, especially in infants, in recent years, there has been a remarkable increase in the use of proton pump inhibitors. In a retrospective study, Barron et $\mathrm{al}^{36}$ found that the prevalence of use of proton pump inhibitors increased 4-fold from 2000 to 2003, with a suggested 7.5-fold increase from 1999 to 2004 for infants younger than 12 months. It is necessary to adhere to the correct indications for use of proton pump inhibitors, especially in the pediatric population.

\section{Conclusion}

The efficacy of proton pump inhibitors has been demonstrated in a pediatric population with GERD-related symptoms and conditions. Esomeprazole has been shown to provide good therapeutic effects, with clinical superiority to intragastric $\mathrm{pH}$ control and symptom relief. Several trials have demonstrated the safety and tolerability of esomeprazole in children and adolescents.

\section{Disclosure}

The authors report no conflicts of interest in this work.

\section{References}

1. Vakil N, van Zanten SV, Kahrilas P, Dent J, Jones R; Global Consensus Group. The Montreal definition and classification of gastroesophageal reflux disease (GERD) - a global evidence-based consensus. Am J Gastroenterol. 2006;101:1900-1920.

2. Sherman PM, Hassall E, Fagundes-Neto U, et al. A global, evidencebased consensus on the definition of gastroesophageal reflux disease in the pediatric population. Am J Gastroenterol. 2009;104:1278-1295.

3. Vandenplas Y, Rudolph CD, Di Lorenzo C, et al; North American Society for Pediatric Gastroenterology Hepatology and Nutrition, European Society for Pediatric Gastroenterology Hepatology and Nutrition. Pediatric Gastroesophageal Reflux Clinical Practice Guidelines: Joint Recommendations of the North American Society for Pediatric Gastroenterology, Hepatology, and Nutrition (NASPGHAN) and the European Society for Pediatric Gastroenterology, Hepatology, and Nutrition (ESPGHAN). J Pediatr Gastroenterol Nutr. 2009;49:498-547.

4. Orenstein SR, Shalaby TM, Cohn JF. Reflux symptoms in 100 normal infants: diagnostic validity of the infant gastroesophageal reflux questionnaire. Clin Pediatr (Phila). 1996;35:607-614.

5. Kleinman L, Rothman M, Strauss R, et al. The Infant Gastroesophageal Reflux Questionnaire Revised: development and validation as an evaluative instrument. Clin Gastroenterol Hepatol. 2006;4:588-596.

6. Bohemer CJ, Clinkenberg-Knol EC, Niezen-de Boer MC, et al. Gastroesophageal reflux disease in intellectually disabled individuals: how often, how serious, how manageable? Am J Gastroenterol. 2000;95: $1868-1872$

7. Koivusalo A, Pakarinen MP, Rintala RJ. The cumulative incidence of significant gastrooesophageal reflux in patients with oesophageal atresia with a distal fistula - a systematic clinical, $\mathrm{pH}$-metric, and endoscopic follow-up study. J Pediatr Surg. 2007;42:370-374. 
8. Orenstein SR, Hassal E. Infants and proton pump inhibitors: tribulations, no trials. J Pediatr Gastroenterol Nutr. 2007;45:395-398.

9. Sachs G, Shin JM, Howdwn CW. Review article: the clinical pharmacology of proton pump inhibitors. Aliment Pharmacol Ther. 2006; 23 Suppl 2:2-8.

10. Sostek MB, Chen Y, Andersson T. Effect of timing of dosing in relation to food intake on the pharmacokinetics of esomeprazole. Br J Clin Pharmacol. 2007;64:386-390.

11. Kearns GL, Winter HS. Proton pump inhibitors in pediatrics: relevant pharmacokinetics and pharmacodynamics. $J$ Pediatr Gastroenterol Nutr. 2003;37 Suppl 1:S52-S59.

12. Van der Pol RJ, Smits MJ, van Wijk MP, Omari TI, Tabbers MM, Benninga MA. Efficacy of proton-pump inhibitors in children with gastroesophageal reflux disease: a systematic review. Pediatrics. 2011;127:925-935.

13. Tafuri G, Trotta F, Leufkens HG, Martini N, Sagliocca L, Traversa G. Off-label use of medicines in children: can available evidence avoid useless paediatric trials? The case of proton pump inhibitors for the treatment of gastroesophageal reflux disease. Eur J Clin Pharmacol. 2009;65:209-216.

14. Gunasekaran T, Gupta S, Gremse D, et al. Lansoprazole in adolescent with gastroesophageal reflux disease: pharmacokinetics, pharmacodynamics, symptom relief efficacy, and tolerability. $J$ Pediatr Gastroenterol Nutr. 2002;35 Suppl 4:S327-S335.

15. Lang L. FDA approves Nexium for use in children aged 1-11 years. Gastroenterology. 2008;134:1282.

16. Andersson T, Hassan-Alin M, Hasselgren G, Röhss K, Weidolf L. Pharmacokinetic studies with esomeprazole, the (S)-isomer of omeprazole. Clin Pharmacokinet. 2001;40:411-426.

17. Röhss K, Hasselgren G, Hedenström H. Effect of esomeprazole $40 \mathrm{mg}$ vs omeprazole $40 \mathrm{mg}$ on 24 -hour intragastric $\mathrm{pH}$ in patients with symptoms of gastroesophageal reflux disease. Dig Dis Sci. 2002;47:954-958.

18. Miner P Jr, Katz PO, Chen Y, et al. Gastric acid control with esomeprazole, lansoprazole, omeprazole, pantoprazole, and rabeprazole: a five-way crossover study. Am J Gastroenterol. 2003;98:2616-2620.

19. McDonagh MS, Carson S, Thakurta S. Drug Class Review: Proton Pump Inhibitors, Final Report Update 5. Portland, OR: Oregon Health and Science University; 2009.

20. Litalien C, Théorêt Y, Faure C. Pharmacokinetics of proton pump inhibitors in children. Clin Pharmacokinet. 2005;44:441-466.

21. Gunasekaran T, Tolia V, Colletti RB, et al. Effects of esomeprazole treatment for gastroesophageal reflux disease on quality of life in 12- to 17-year-old adolescents: an international health outcomes study. $B M C$ Gastroenterol. 2009;9:84.

22. Tolia V, Youssef NN, Gilger MA, Traxler B, Illueca M. Esomeprazole for the treatment of erosive esophagitis in children: an international, multicenter, randomized, parallel-group, double-blind (for dose) study. BMC Pediatr. 2010;10:41.
23. Zhao J, Li J, Hamer-Maansson JE, et al. Pharmacokinetic properties of esomeprazole in children aged 1 to 11 years with symptoms of gastroesophageal reflux disease: a randomized, open-label study. Clin Ther. 2006;28:1868-1876.

24. Gilger MA, Tolia V, Vandenplas Y, Youssef NN, Traxler B, Illueca M. Safety and tolerability of esomeprazole in children with gastroesophageal reflux disease. J Pediatr Gastroenterol Nutr. 2008;46: 524-533.

25. Gold BD, Gunasekaran T, Tolia V, et al. Safety and symptom improvement with esomeprazole in adolescents with gastroesophageal reflux disease. J Pediatr Gastroenterol Nutr. 2007;45:520-529.

26. Hassall E, Kerr W, El-Serag HB. Characteristics of children receiving proton pump inhibitors continuously for up to 11 years duration. J Pediatr. 2007;150:262-267.

27. Tolia V, Boyer K. Long-term proton pump inhibitor use in children: a retrospective review of safety. Dig Dis Sci. 2008;53:385-393.

28. Turco R, Martinelli M, Miele E, et al. Proton pump inhibitors as a risk factor for paediatric Clostridium difficile infection. Aliment Pharmacol Ther. 2010;31:754-759.

29. Canani RB, Cirillo P, Roggero P, et al; Working Group on Intestinal Infections of the Italian Society of Pediatric Gastroenterology, Hepatology and Nutrition. Therapy with gastric acidity inhibitors increases the risk of acute gastroenteritis and community-acquired pneumonia in children. Pediatrics. 2006;117:e817-e820.

30. McColl KE. Effect of proton pump inhibitors on vitamins and iron. $\mathrm{Am}$ J Gastroenterol. 2009;104 Suppl 2:S5-S9.

31. Yang YX, Lewis JD, Epstein S, Metz DC. Long-term proton pump inhibitor therapy and risk of hip fracture. JAMA. 2006;296:2947-2953.

32. Thomson AB, Sauve MD, Kassam N, Kamitakahara H. Safety of the long-term use of proton pump inhibitors. World J Gastroenterol. 2010;16:2323-2330.

33. Hassall E, Owen D, Kerr W, Sturby T, Richardson P, El-Serag H. Gastric histology in children treated with proton pump inhibitors long term, with emphasis on enterochromaffin cell-like hyperplasia. Aliment Pharmacol Ther. 2011;33:829-836.

34. Vermeer IT, Engels LG, Pachen DM, Dallinga JW, Kleinjans JC, van Maanen JM. Intragastric volatile N-nitrosamines, nitrite, $\mathrm{pH}$, and Helicobacter pylori during long-term treatment with omeprazole. Gastroenterology. 2001;121:517-525.

35. Romano C, Chiaro A, Comito D, Loddo I, Ferrau V. Proton pump inhibitors in pediatrics: evaluation of efficacy in GERD therapy. Curr Clin Pharmacol. 2011;16:41-47.

36. Barron JJ, Tan H, Spalding J, et al. Proton pump inhibitor utilization patterns in infants. J Pediatr Gastroenterol Nutr. 2007;45:421-427.

Adolescent Health, Medicine and Therapeutics

\section{Publish your work in this journal}

Adolescent Health, Medicine and Therapeutics is an international, peer-reviewed, open access journal focusing on health, pathology, and treatment issues specific to the adolescent age group. All aspects of health maintenance, preventative measures and disease treatmen interventions are addressed within the journal and practitioners from

all disciplines are invited to submit their work as well as healthcare researchers and patient support groups.. The manuscript management system is completely online and includes a very quick and fair peerreview system. Visit http://www.dovepress.com/testimonials.php to read real quotes from published authors. 